\title{
Perventricular device closure of muscular ventricular septal defects on the beating heart: Technique and results
}

\author{
Emile A. Bacha, MD \\ Qi-Ling Cao, MD ${ }^{\mathrm{b}}$ \\ Joanne P. Starr, MD \\ David Waight, $M D^{\mathrm{b}}$ \\ Makram R. Ebeid, MD ${ }^{c}$ \\ Ziyad M. Hijazi, MD
}

Objective: Both surgical management and percutaneous device closure of muscular ventricular septal defects have drawbacks and limitations. This report describes our initial experience with intraoperative device closure of muscular ventricular septal defects without cardiopulmonary bypass in 6 consecutive patients.

Methods: A median sternotomy or a subxiphoid minimally invasive incision was performed. Under continuous transesophageal echocardiographic guidance, the right ventricle free wall was punctured, and a wire was introduced across the largest defect. The Amplatzer (AGA Medical Corporation, Golden Valley, Minn) muscular ventricular septal defect occluding device (a self-expandable double-disk device) was used. An introducer sheath was fed over the wire, with the sheath tip positioned in the left ventricle cavity. The device was then advanced inside the sheath and deployed by retracting the sheath. Associated cardiac lesions, if any, can then be repaired during cardiopulmonary bypass. A similar technique can also be applied for periatrial closure of complex atrial septal defects.

Results: The initial 6 patients are presented. Cardiopulmonary bypass was not needed in any patient for placement of the device and needed in 4 patients for repair of concomitant malformations only (double-outlet right ventricle, aortic arch hypoplasia, pulmonary artery band removal). No complications from using this technique occurred. Discharge echocardiograms showed no significant shunting across the ventricular septum.

Conclusions: Perventricular closure of multiple muscular ventricular septal defects is safe and effective. We believe that this could become the treatment of choice for any infant with muscular ventricular septal defects or any child with muscular ventricular septal defect and associated cardiac defects.

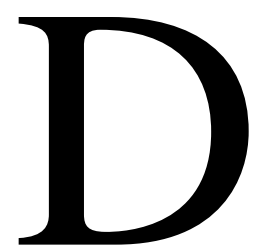

espite recent improvements, ${ }^{1,2}$ surgical therapy of muscular ventricular septal defects (MVSDs), especially when multiple or requiring left ventriculotomy for closure, is still associated with significant long-term morbidity and mortality. ${ }^{1-3}$ When present with other complex heart lesions such as double-outlet right ventricle (DORV), for example, multiple MVSDs have been found to be an independent risk factor for early mortality. ${ }^{4,5}$ In the long-term, heart transplantation is sometimes required because of persistent ventricular dysfunction. ${ }^{1,2,6}$ Recent results of percutaneous device closure of MVSDs have been very encouraging. ${ }^{7}$ However, the percutaneous approach can be challenging because of 

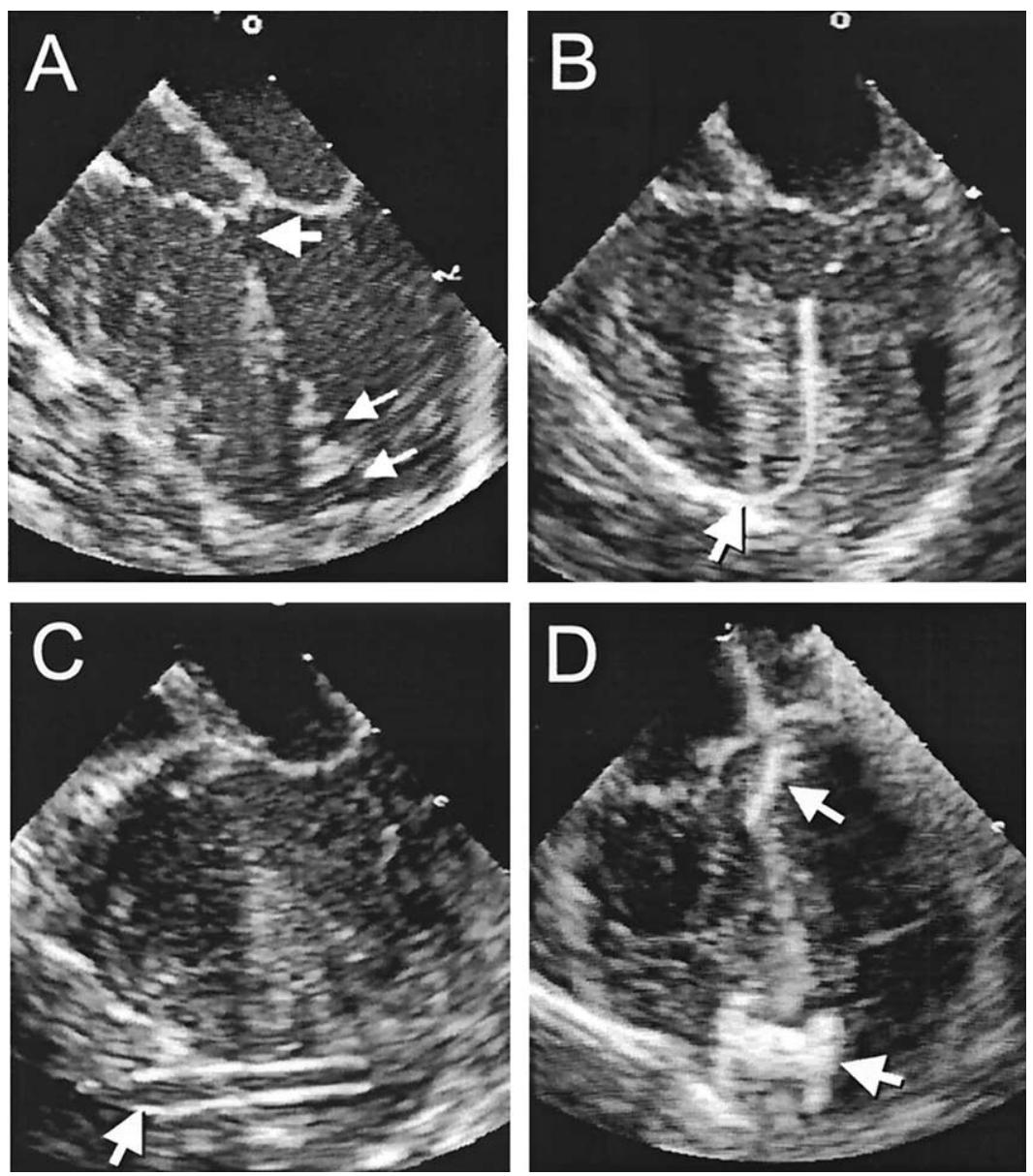

Figure 1. Perventricular VSD device closure in an infant with DORV, pulmonary stenosis, subaortic VSD, and multiple muscular apical VSDs. (A) Multiple apical defects (smaller arrows) and subaortic VSD (large arrow). (B) The wire is positioned across the largest apical defect. (C) The sheath is positioned with its tip in the LV cavity. The device is then pushed in and deployed by slowly pulling the sheath back. (D) Postoperative TEE. The device has been deployed, and the subaortic VSD patch can also be seen in place.

low patient weight (infants $<5 \mathrm{~kg}$ ) or poor vascular access. In addition, in small infants, the passage of large delivery catheters may result in rhythm disturbances and hemodynamic compromise. Efforts have been made to combine catheterization and surgical techniques. Four series of intraoperative closure using double-umbrella devices have been reported. ${ }^{6,8-10}$ Overall results were not satisfactory, with mortality and failure rates of $14 \%$ to $25 \%$ and $20 \%$ to $40 \%$, respectively. The common approach to all was that the devices were placed under direct vision, after cardiopulmonary bypass (CPB) and cardioplegic arrest. Some deaths resulted from residual shunting and from low cardiac output despite complete closure.

This report describes our consecutive experience with a technique that does not require CPB to deal with this difficult clinical problem. The device used was the Amplatzer congenital MVSD device (AGA Medical Corporation,
Golden Valley, Minn), a self-expandable double-disk device made from nitinol wire mesh. The device size corresponds to the waist ( $7 \mathrm{~mm}$ long) diameter of the device. Both left ventricle (LV) and RV disks are $4 \mathrm{~mm}$ larger than the waist.

\section{Material and Methods}

The heart was approached through a median sternotomy or, as in the latest patient, a subxiphoid minimally invasive incision without sternotomy. Under continuous transesophageal echocardiography (TEE) guidance, the best location for RV puncture was chosen, being careful to stay away from any papillary muscles but far enough from the septum so as to approach it from a perpendicular angle with the needle and wire (Figures 1 and 2). A 5-0 polypropylene purse-string was placed at the chosen location. An $18-\mathrm{G}$ needle (Cook Inc, Bloomington, Ind) was introduced into the RV 

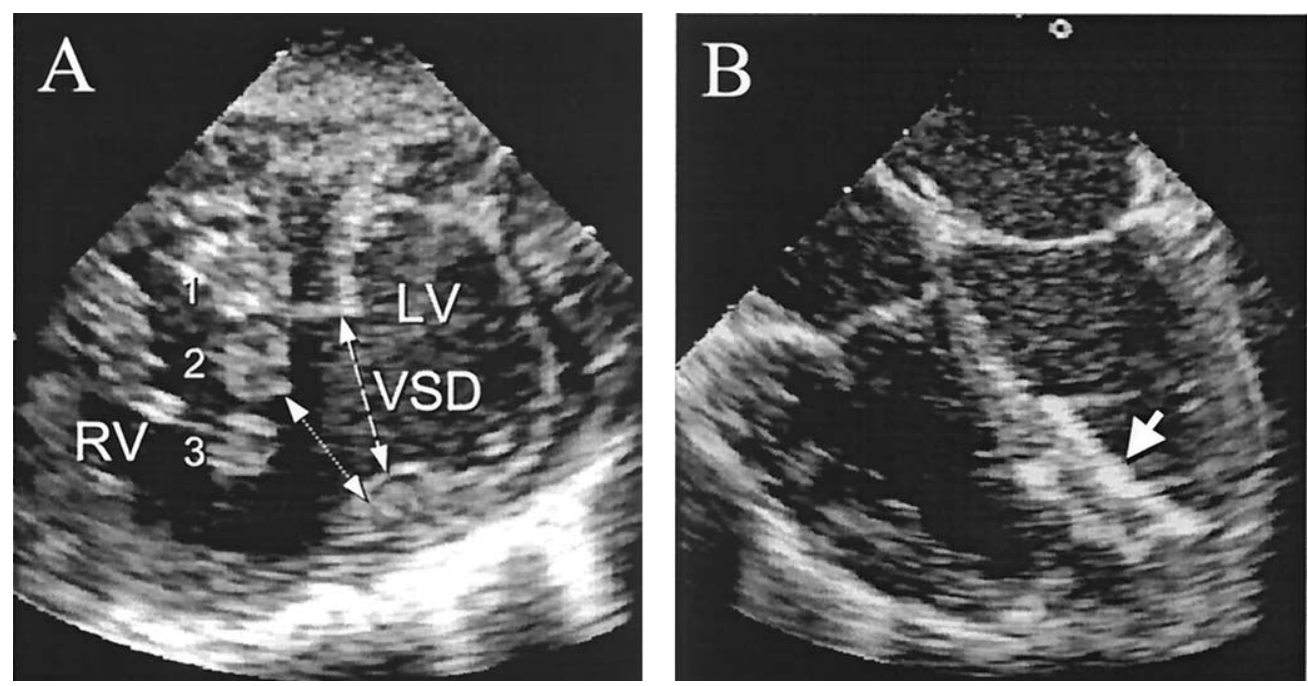

Figure 2. Perventricular VSD device closure in a banded child with multiple right-sided apical openings converging into a single large left-sided opening. (A) Short-axis view of the apical septum. The inferior edge of the moderator band (2) could be easily mistaken for the superior edge of the VSD (dotted arrow). In fact, the true superior/anterior border of the VSD extends further (dashed arrow). It becomes clear that multiple openings on the right converge into a single very large VSD on the left. (1) Posterior papillary muscle, (2) moderator band, (3) anterior papillary muscle. (B) The LV disk is deployed, occluding the single left-sided opening. The RV disk was deployed within the apical RV trabeculations.

cavity and directed toward the defect to be closed. A 0.035 -inch angled glide wire (Boston Scientific; Medi-Tech, Natick, Mass) was passed through the needle and manipulated into the LV cavity through the defect. The needle was then removed keeping the wire in location. A $7 \mathrm{~F}$ to $10 \mathrm{~F}$ short $(8-13 \mathrm{~cm})$ introducer sheath with a dilator was fed over the wire and carefully advanced into the LV cavity. Care must be taken not to go too deep into the heart because the introducer and dilator are stiff instruments made for percutaneous puncture and thus are quite long and could easily perforate the LV wall despite being guided by the wire (straightening of the wire by the dilator). The dilator was removed, and the sheath tip was positioned in the LV cavity (Figure 1C). The appropriate device size was chosen to be 1 to $2 \mathrm{~mm}$ larger than the VSD size as assessed by TEE. The device was presoaked in nonheparinized blood for 10 minutes to allow for the tiny fenestrations of the nitinol mesh to thrombose. The device was then screwed to the cable and pulled inside a 6-9 Fr loader under blood seal to prevent any air bubbles. The device was advanced inside the short delivery sheath until it was seen by TEE to be close to the tip of the delivery sheath. The LV disk was deployed in mid-LV cavity by gentle retraction of the sheath over the cable. The entire assembly (cable/ sheath) was withdrawn gently until the LV disk was against the septum. Further retraction of the sheath over the cable would deploy the waist inside the septum. Continuous TEE to confirm the device position is of paramount importance. Once the position was confirmed, further retraction of the sheath to expand the RV disk was performed. If device position was satisfactory, the device was released by counterclockwise rotation of the cable using the pin vise. A complete TEE study in multiple planes was performed to confirm device placement, assess for residual shunting, and discern any obstruction or regurgitation induced by the device.

\section{Clinical Summaries}

Informed consent was obtained from the patients' guardians. The study was approved by the hospital investigation review board and was part of a Food and Drug Administration Investigation Device Exemption clinical trial. The study started in September 2002. Selection criteria were (1) the presence of cardiac lesions necessitating operative repair (in addition to an MVSD) and (2) patients with contraindications to percutaneous device closure of MVSDs (eg, infants or patients with poor vascular access).

No patient was converted from a perventricular approach to an open approach. Standard pediatric cardiac surgical intraoperative and postoperative monitoring were used (Table 1).

\section{Discussion}

One successful case of intraoperative perventricular device closure on the beating heart has been reported in a baby. ${ }^{12}$ This is the first reported series of consecutive intraoperative VSD device closure without CPB. In previous reports of intraoperative device closures, the difficulties in delivering the device or having to suture the device were specifically quoted as a factor in poor outcomes. ${ }^{6,8,9}$ The present technique's safety has been validated in animal experiments. ${ }^{13}$ Although not formally measured, the time needed to cross the VSD and position the device was less than 20 minutes in all cases. This compares very favorably with the longer procedure times when the equivalent maneuver is attempted in the catheterization laboratory. An advantage of this tech- 
TABLE 1. Patients who underwent perventricular ventricular septal defect device closure, in chronologic order

\begin{tabular}{|c|c|c|c|c|c|c|}
\hline Patient & Age/weight & Diagnosis & $\begin{array}{l}\text { Preoperative } \\
\text { symptoms }\end{array}$ & Exposure & Device size & Additional procedures \\
\hline 1 & $5 \mathrm{mo}, 7 \mathrm{~kg}$ & $\begin{array}{l}\text { DORV, subaortic VSD, } \\
\text { sub-PS/PS, multiple } \\
\text { apical VSDs }\end{array}$ & No & $\begin{array}{l}\text { Median } \\
\text { sternototomy }\end{array}$ & $8 \mathrm{~mm}$ & $\begin{array}{l}\text { Subaortic/VSD patch, } \\
\text { pulmonary valvotomy, } \\
\text { infundibular patch }\end{array}$ \\
\hline 2 & $20 \mathrm{~d}, 3 \mathrm{~kg}$ & $\begin{array}{l}\text { Aortic coarctation + } \\
\text { arch hypoplasia; } \\
\text { large anterior } \\
\text { muscular VSD, tiny } \\
\text { apical VSD, LV } \\
\text { hypoplasia, and } \\
\text { dysfunction }\end{array}$ & $\begin{array}{l}\text { Metabolic } \\
\text { acidosis, } \\
\text { cardiogenic } \\
\text { shock }\end{array}$ & $\begin{array}{l}\text { Median } \\
\text { sternototomy }\end{array}$ & $6 \mathrm{~mm}$ & $\begin{array}{l}\text { Coarctation repair and } \\
\text { arch augmentation }\end{array}$ \\
\hline 3 & $4 \mathrm{mo}, 4 \mathrm{~kg}$ & $\begin{array}{l}\text { Large anterior muscular } \\
\text { VSD, ASD (multiple } \\
\text { fenestrations) (b) }\end{array}$ & FTT, CHF & $\begin{array}{l}\text { Partial lower } \\
\text { sternototomy }\end{array}$ & $\begin{array}{l}10 \mathrm{~mm} \text { (VSD) } \\
11 \mathrm{~mm} \text { (ASD) }\end{array}$ & No \\
\hline 4 & $2.5 \mathrm{y}, 12 \mathrm{~kg}$ & $\begin{array}{l}\text { s/p PA band for } \\
\text { multiple apical VSDs }\end{array}$ & No & $\begin{array}{l}\text { Median } \\
\text { sternototomy }\end{array}$ & $18 \mathrm{~mm}$ & $\begin{array}{l}\text { Band removal and PA } \\
\text { plasty }\end{array}$ \\
\hline 5 & $17 \mathrm{~d}, 3 \mathrm{~kg}$ & $\begin{array}{l}\text { Large anterior muscular } \\
\text { VSD }\end{array}$ & $\mathrm{CHF}$ & $\begin{array}{l}\text { Xiphoid } \\
\text { incision }\end{array}$ & $12 \mathrm{~mm}$ & No \\
\hline 6 & $3 y, 20 \mathrm{~kg}$ & $\begin{array}{l}\text { DORV, TGA, inlet. VSD, } \\
\text { apical muscular VSD, } \\
\text { LV hypoplasia, s/p PA } \\
\text { band, and BDG }\end{array}$ & No & $\begin{array}{l}\text { Median } \\
\text { sternototomy }\end{array}$ & $14 \mathrm{~mm}$ & $\begin{array}{l}\text { VSD enlargement and } \\
\text { LV-aortic baffle, t/d } \\
\text { BDG (e) }\end{array}$ \\
\hline
\end{tabular}

$A S D$, Atrial septal defect; $B D G$, bidirectional Glenn shunt; $C H F$, congestive heart failure; $C P B$, cardiopulmonary bypass; $D / C$, discharge; $L V$, left ventricle; $P A$, pulmonary artery; $P S$, pulmonary stenosis; $P O D$, postoperative day; $R V$, right ventricle; $s / p$, status post; $t / d$, take-down; $V S D$, ventricular septal defect; $O p / O$ s, left-to-right shunt ratio; $D O R V$, double-outlet right ventricle; TGA, transposition of great arteries; FTT, failure to thrive; ECMO, extracorporeal membrane oxygenation; TEE, transesophageal echocardiography; URI, upper respiratory tract infection.

(a) Cardiopulmonary bypass was needed only for additional procedures, not for placement of the device, which was performed first in patients 1, 2, 3, and 5 and after PA band removal in patient 4 . In patient 6, perventricular closure was accomplished during bypass because the decision to do it was made during bypass.

(b) TEE showed that the atrial septum had multiple separate openings. By using an aortic punch introduced through a right atrial puncture, a central hole was created in the floppy septum primum. By use of the technique described, an 11-mm Amplatzer (AGA Medical Corp, Golden Valley, Minn) septal occluder was positioned and deployed centrally in the ASD.

(c) The LV disk obliterated the entire left apical septum, resulting in no residual shunting. However, the RV disk was difficult to deploy because of the severely hypertrophied moderator band and apical RV muscle bundles, which essentially filled the entire RV apex (infundibulosinus partition) ${ }^{11}$ and prevented the expansion of the RV disk. The RV disk was eventually positioned within the apical muscle bundles with the device microscrew protruding through the RV free wall puncture site (Figure 4). The screw was secured to the epicardium with a pledget-supported suture. Op/Qs at the end of the procedure was 1.5 .

(d) This patient was readmitted to his primary hospital 2 weeks postoperatively with nonspecific URI. A catheterization showed the 4-mm residual VSD again with a $0 \mathrm{p} / 0 \mathrm{~s}$ of 1.9 . He was discharged after receiving diuretics and afterload-reducing therapy for 24 hours. At 4 months postoperative, he is asymptomatic, and the residual VSD is down to $2 \mathrm{~mm}$ with no ventricular enlargement.

(e) On preoperative studies, the apical muscular VSD had been judged to be insignificant and was left alone initially. Failure to come off of cardiopulmonary bypass after biventricular repair and evidence of significant left-right shunting across the muscular VSD by TEE led to the decision to close VSD with the perventricular technique. This was successful in that the muscular VSD was found to be completely occluded by TEE and the patient was weaned off of CPB. LV hypoplasia prevented successful biventricular repair, and after a 24-hour period of rest on ECM0, the repair was taken-down to an extracardiac Fontan.

nique compared with standard surgical techniques is the avoidance of CPB in patients who often have ventricular dysfunction. If associated cardiac lesions are present, a marked reduction in $\mathrm{CPB}$ and cardioplegic arrest time is achieved. As illustrated in patient 6, perventricular device closure of a previously underestimated MVSD resulted in avoidance of repeated cardiologic arrest in a patient who already had a long crossclamp time. Other advantages in- clude avoidance of transection of the moderator band or other RV muscle bundles, immediate confirmation of adequate closure, and avoidance of any ventricular incisions. In the absence of associated defects, a minimally invasive approach, such as a subxiphoid incision $(1-2 \mathrm{~cm})$, can be easily used (patient 5). Compared with percutaneous approaches, it has no weight and no vascular access limitations. Particularly in malformations with unusual septal 
TABLE 1. Continued

\begin{tabular}{|c|c|c|c|c|c|c|c|}
\hline $\begin{array}{l}\text { CPB } \\
\text { (a) }\end{array}$ & $\begin{array}{c}\text { Cardioplegic } \\
\text { arrest }\end{array}$ & $\begin{array}{l}\text { Intraoperative } \\
\text { complications }\end{array}$ & $\begin{array}{c}\text { Op/ } \\
\text { Os }\end{array}$ & $\begin{array}{l}\text { Postoperative } \\
\text { complications }\end{array}$ & $\begin{array}{l}\mathrm{D} / \mathrm{C} \\
\text { day }\end{array}$ & $\begin{array}{c}\text { D/C } \\
\text { echocardiograph }\end{array}$ & $\begin{array}{c}\text { Status at } \\
\text { follow-up (mo) }\end{array}$ \\
\hline Yes & Yes & No & 1.2 & No & 6 & No shunt & $\begin{array}{l}\text { Asymptomatic } \\
\text { (7) }\end{array}$ \\
\hline Yes & No & No & 1.1 & No & 20 & $\begin{array}{c}\text { Minimal shunt } \\
\text { across tiny } \\
\text { apical VSD }\end{array}$ & $\begin{array}{l}\text { Asymptomatic } \\
\text { (6) }\end{array}$ \\
\hline
\end{tabular}

\begin{tabular}{|c|c|c|c|c|c|c|c|}
\hline No & No & No & 1.2 & No & 3 & No shunt & $\begin{array}{l}\text { Asymptomatic } \\
\text { (4) }\end{array}$ \\
\hline Yes & No & $\begin{array}{l}\text { Difficult deployment } \\
\text { of RV disk (c) } \\
\text { (microscrew } \\
\text { protrusion) }\end{array}$ & 1.5 & $\begin{array}{l}\text { POD 1: Reintubation } \\
\text { for reperfusion } \\
\text { pulmonary edema }\end{array}$ & 7 & $\begin{array}{l}4 \mathrm{~mm} \text { residual } \\
\text { VSD at device } \\
\text { edge (d) }\end{array}$ & $\begin{array}{l}\text { Asymptomatic } \\
\quad \text { residual } \\
\text { VSD now } 2 \\
\text { mm (4) }\end{array}$ \\
\hline No & No & No & 1.2 & No & 4 & No shunt & $\begin{array}{l}\text { Asymptomatic } \\
\text { (3) }\end{array}$ \\
\hline Yes & Yes & $\begin{array}{l}\text { LV failure, ECMO; } \\
\text { t/d of repair, } \\
\text { removal of device } \\
\text { and Fontan }\end{array}$ & 1.1 & Pleural effusions & 20 & $\begin{array}{l}\text { Widely patent } \\
\text { ASD and VSD }\end{array}$ & $\begin{array}{l}\text { Asymptomatic } \\
\text { (2) }\end{array}$ \\
\hline
\end{tabular}

planes such as DORV or transposition of the great arteries, the percutaneous retrograde approach to cross MVSDs can be very challenging. This technique eliminates that issue because the septum is approached from an anterior and not a lateral (tricuspid valve) plane. In addition, percutaneous closure of MVSDs in a child palliated with a pulmonary artery (PA) band often results in residual shunting after the PA band is removed. ${ }^{7}$ As illustrated in patient 4 , the present technique offers the possibility to deband the PA and close all VSDs using the perventricular approach in 1 setting. As we also experienced with patient 4 , severely hypertrophied $\mathrm{RV}$ muscle bundles make the recognition of the true VSD margins and correct deployment of the RV disk difficult. This strengthens our belief that patients with MVSDs should not be palliated but closed at the time of initial presentation. Post-infarct VSDs in adults would also be amenable to this approach whereby one would be able to avoid prolonged cardioplegic arrest and revascularize the patient in 1 setting. Furthermore, we have described the first periatrial device closure of a complex atrial septal defect (ASD). This approach may be used as an alternative to traditional ASD closure during CPB in patients with complex ASDs caused by large atrial septal aneurysms or in large ASDs in which attempts to align the left atrial disk parallel to the septum may fail because of the angle of approach.

\section{Conclusion}

Despite the limitations of this study (small patient sample, short follow-up, and lack of randomization), this report demonstrates the feasibility of off-pump MVSD closure through right perventricular puncture using the Amplatzer MVSD device. We believe that this technique may become the initial treatment of choice for any infant with MVSDs, for older patients with poor vascular access, and for patients previously palliated with PA bands. As hybrid cardiac surgery techniques mature, thoracoscopic or robotic puncture of the RV or the right atrium and device delivery into a VSD or ASD may be a reality in the near future.

\section{References}

1. Kitagawa T, Durham LA, Mosca RS, Bove EL. Techniques and results in the management of multiple ventricular septal defects. $J$ Thorac Cardiovasc Surg. 1998;115:848-56.

2. Seddio F, Reddy VM, McElhinney DB, Tworetzky W, Silverman NH, Hanley FL. Multiple ventricular septal defects: how and when should they be repaired? J Thorac Cardiovasc Surg. 1999;117:134-40.

3. Serraf A, Lacour-Gayet F, Bruniaux J, Ouaknine R, Losay J, Petit J, et al. Surgical management of isolated multiple ventricular septal defects. Logical approach in 130 cases. J Thorac Cardiovasc Surg. 1992;103: 437-42.

4. Kleinert S, Sano T, Weintraub RG, Mee RBB, Karl TR, Wilkinson JL. Anatomic features and surgical strategies in double-outlet right ventricle. Circulation. 1997;96:1233-9.

5. Aoki M, Forbess JM, Jonas RA, Mayer JE Jr, Castaneda AR. Results of biventricular repair for double-outlet right ventricle. $J$ Thorac Cardiovasc Surg. 1994;107:338-50. 
6. Okubo M, Benson LN, Nykanen D, Azakie A, Van Arsdell G, Coles $\mathrm{J}$, et al. Outcomes of intraoperative device closure of muscular ventricular septal defects. Ann Thorac Surg. 2001;72:416-23.

7. Waight DJ, Bacha EA, Kahana M, Cao QL, Heitschmidt M, Hijazi ZM. Catheter therapy of swiss cheese ventricular septal defects using the Amplatzer muscular VSD occluder. Catheter Cardiovasc Interv. 2002;55:355-61.

8. Fishberger SB, Bridges ND, Keane JF, Hanley FL, Jonas RA, Mayer $\mathrm{JE}$, et al. Congential heart disease: intraoperative device closure of ventricular septal defects. Circulation. 1993;88:II205-9.

9. Murzi B, Bonanomi GL, Giusti S, Luisi VS, Bernabei M, Carminati M, et al. Surgical closure of muscular VSD using double umbrella devices (intraoperative VSD device closure). Eur J Cardiothorac Surg. 1997; $12: 450-5$.
10. Chaturvedi RR, Shore DF, Yacoub M, Redington AN. Intraoperative apical ventricular septal defect closure using a modified Rashkind double umbrella. Heart. 1996;76:367-9.

11. Van Praagh S, Mayer JE Jr, Berman NB, Flanagan MF, Geva T, Van Praagh R. Apical ventricular septal defects: follow-up concerning anatomic and surgical considerations. Ann Thorac Surg. 2002;73:4857.

12. Amin Z, Berry JM, Foker JE, Rocchini AP, Bass JL. Intraoperative closure of muscular ventricular septal defect in a canine model and application of the technique in a baby. J Thorac Cardiovasc Surg. 1998;115:1374-6.

13. Amin Z, Gy X, Berry JM, Bass JL, Titus JL, Urness M, et al. New device for closure of muscular ventricular septal defects in a canine model. Circulation. 1999;100:320-8.

\section{Online-www.aats.org}

Now you can get The Journal of Thoracic and Cardiovascular Surgery online. The Journal online brings you faster delivery time, easy searching of current and back issues, links to PubMed, AATS, WTSA, and other important sites, and more. Visit the Journal online today.

\section{Receive tables of contents by e-mail}

To receive the tables of contents by e-mail, sign up through our Web site at http://www.mosby.com/jtcvs

Choose E-mail Notification

Simply type your e-mail address in the box and click the Subscribe button.

Alternatively, you may send an e-mail message to majordomo@mosby.com.

Leave the subject line blank and type the following as the body of your message: subscribe jtcvs_toc

You will receive an e-mail to confirm that you have been added to the mailing

list.

Note that TOC e-mails will be sent out when a new issue is posted to the Web site. 